\title{
The Role of Connectedness for Minoritized Students at a Mentoring Conference
}

\section{Ms. Carin Queener, University of Michigan}

Carin Queener is a rising senior in the department of Industrial and Operations Engineering.

\section{Dr. Joi-Lynn Mondisa, University of Michigan}

Joi Mondisa is an Assistant Professor in the Department of Industrial and Operations Engineering and an Engineering Education Faculty Member at the University of Michigan-Ann Arbor. Dr. Mondisa holds a PhD in Engineering Education, an MS in Industrial Engineering, an MBA, and a BS in General Engineering. She researches STEM mentoring experiences and mentoring intervention programs in higher education.

\section{Dr. Dorian Davis,}

Dr. Dorian Davis is the Owner of Walker Davis Consulting Group, a student success centered company assisting kindergarten-higher education leaders, corporations and organizations transform lives through academic course development, process and system improvement and professional development. Most recently, Dr. Davis was the Program Specialist for the ADVANCE Faculty Development grant and the Sr. IT Analyst and Designer in Information Technology Services for North Carolina A\&T State University. Prior to joining higher education, she spent nearly two decades in corporate leadership and engineering working with companies and government agencies such as 3M, Ford Motor Company, Chrysler Corporation and the National Science Foundation.

Dr. Davis received her PhD in Industrial and Systems Engineering from North Carolina A\&T State University, M.S. degree in Industrial Engineering from Purdue University and B.S. degree in Industrial Engineering from North Carolina A\&T State University. Dr. Davis has received numerous honors and awards.

\section{Dr. Renaldo C. Blocker, The "Why You?" Initiative, Inc.}

Dr. Renaldo C. Blocker is an Associate Consultant and Assistant Professor in the Department of Healthcare Systems Engineering and in the Mayo Clinic's Center for the Science of Health Care Delivery (Rochester, MN). He's the Co-Founder of the "Why You?" Initiative, Inc.

He earned his Ph.D (2012) and a Masters (2010) from the University of Wisconsin-Madison in Industrial and Systems Engineering concentrating in Human Factors and Ergonomics. Also, Dr. Blocker received a master's degree (2006) in Computer Science from San Francisco State University. He attended Albany State University (Albany, GA) where he obtained a bachelor's degree (2003) in Computer Science. He conducts research studies to ameliorate complex healthcare system issues by redesigning processes, tools and technologies. 


\title{
The Role of Connectedness for Minoritized Students at a Mentoring Conference
}

\author{
Carin Queener ${ }^{1}$, Joi-Lynn Mondisa ${ }^{1}$, Dorian Davis ${ }^{2}, \&$ Renaldo Blocker ${ }^{3}$ \\ ${ }^{1}$ Department of Industrial and Operations Engineering, University of Michigan \\ ${ }^{2}$ Consultant, Greensboro, NC \\ ${ }^{3}$ Mayo Clinic, Rochester, MN
}

\begin{abstract}
Multiple research studies have highlighted a variety of compounding factors (e.g., academic and social isolation, confronting unwelcoming climates) which contribute to the small numbers of Black students in STEM higher education. Mentoring has been shown to help support minoritized populations and their development of a sense of belonging. Formal mentoring programs, which provide social support, and access to mentors, peers, and resources, help to mitigate issues of isolation. In this exploratory study, we investigate the effects of The "Why You?” Initiative, Inc. [YU?] Biannual Spring Confab - a conference designed to facilitate excellence and professional/academic development among minoritized populations. We examine conference participants' connectedness, that is, how linked a participant feels to the community. Eleven participants completed a pre- and post- survey featuring statements and open-ended questions about their experience. Preliminary findings indicate that conference attendance generally increased participants' connectedness, although students desired more networking time. Subsequently, the conference should be repeated and allow more time for interactions.
\end{abstract}

\section{Introduction}

Jobs in science, technology, engineering, and mathematics (STEM) fields are some of the highest in demand positions in the world today, and more students will need to be recruited to pursue STEM degrees in order to meet the growing need [1]. Notably, Blacks/African Americans make up about $14 \%$ of the United States population [2], but in 2011, only $6 \%$ of STEM workers were Black [3]. In 2017, Black or African American students only made up 4.51\% of enrolled engineering undergraduates, and that portion shrank for higher education - they made up only $1.64 \%$ of enrolled doctoral students in engineering, figures that would have also included international African students [4]. This problem extends beyond just engineering. In 2017, there were more than a dozen fields - largely subfields within science, technology, engineering, and math - in which not a single doctoral degree was awarded to a Black person anywhere in the United States [5]. Thus, not only are there few Black students pursuing STEM degrees, even fewer continue on to pursue higher levels of education, and as a group, Blacks are significantly underrepresented in the STEM workforce.

There are many factors that contribute to the small numbers of Black students in STEM fields. Having a sense of community stands out as one of the defining factors. Notably, historically 
Black colleges and universities (HBCUs) produced 25\% of all bachelor's degrees in STEM fields earned by African Americans in 2012 [6]. Additionally, more than a third of Black STEM $\mathrm{Ph} . \mathrm{D}$. holders earned their undergraduate degrees at HBCUs [5]. However, some institutions may lack nurturing communities, which may affect students' access to resources. In a study by Burt, Williams, \& Smith (2018) [7], despite knowing that they should be in a study group and having an interest in joining one, Black males at three predominantly White institutions (PWIs) found it difficult to gain access to the study groups dominated by their White and international Asian peers. In some cases, they were not invited or they were rejected. Instead, most Black males relied on community-based organizations, fraternities, and mentoring groups. Also, students of color might not have adequate access to role models of the same race due to a lack of faculty of color at certain academic institutions [8].

A lack of community may correlate to underrepresentation and can contribute to confronting stereotypes and encountering mental strain. In one example, the underrepresentation of Black males within a College of Engineering was a source of non-normative student role strain for many of these students [7]. Additionally, the culture of origin of minoritized students differs from academic culture. Thus, minoritized students may experience being in a predominantly White environment for the first time, or they may be the first in their family to attend college, causing the environment to be unfamiliar and more difficult to navigate [9]. Some campus climates might be unwelcoming to minoritized students [10,11]. In addition, students of color at PWIs might face obstacles that could contribute to feelings of social or academic isolation and negatively impact their performance [12, 13, 14].

While a lack of community can contribute to several far-reaching problems, mentoring and having a community have been shown to be mechanisms that provide students with psychosocial and emotional support and well-being. Students of color who participate in formal mentoring programs providing social support and access to faculty, peers, and resources may have beneficial long-term outcomes $[15,16]$. In one study, students in focus groups reported that their involvement in a pre-college summer program for Black STEM students helped them achieve academic, social, and professional expectations [17]. Specifically, entering college having a network of peers, faculty and administrators gave students access to resources they might not have otherwise utilized, in addition to a sense of family. Likewise, there are numerous examples of successful mentoring programs in higher education like the Meyerhoff Scholars Program [18], the Merit Program for Emerging Scholars at the University of Illinois at Urbana-Champaign [19], the Adventor Program [20] and others.

Generally, there are three primary components to a mentoring program: (a) program values, (b) access to faculty and peers, and (c) formal and informal group activities [15, 21, 22, 23, 24, 25]. All three components also connect to community—program values both define a community, but also require community in order to ring true. Access to faculty and peers creates the opportunity 
for connection, and group activities to develop connections. However, there has been minimal research $[15,26]$ that focuses primarily on the experiences of community and its effects on wellbeing for minoritized students, and even less work of practical examples using community theory. Thus, as community plays a central role in the success of Black students in STEM fields, and yet it is under-examined, it was chosen as the focus of this exploratory study.

The purpose of this study is to examine social community elements of the "Why You?" Initiative, Inc. ("[YU?]") organization's mentoring program and conference to assess participants' feelings of connectedness and community. The research question guiding this study is: How did conference attendance affect the experience of connectedness for students? In this paper, we examine the experiences and outcomes of the participants of the organization's mentoring program and conference to help researchers and practitioners understand AfricanAmerican STEM students' experiences of connectedness.

In the following paragraphs, we first provide background information about the [YU?] organization. Then, we briefly discuss social community as a theoretical framework used to understand community development. Next, the research methods and findings of this study are presented. In conclusion, a discussion of the findings that emerged and implications for practice are provided.

\section{The [YU?] organization}

\section{Background}

The [YU?] organization is a hybrid longitudinal support system that engages students via an online platform supplemented by traditional face-to-face interactions with mentors, staff, and peers. Officially established in 2011, [YU?] has a mission to eradicate barriers to students' and young professionals' success by effectively delivering longitudinal support via a fusion of technological and traditional mediums. The organization is devoted primarily to helping underrepresented high school students, post-high school students, undergraduate students, graduate students and young professionals with their academic and professional endeavors. In support of its mission, the organization sponsors and supports a longitudinal mentoring program and an annual physical conference that has been historically primarily attended by for African Americans [30].

The [YU?] mentoring program and conference exposes African-American students to STEM disciplines from a culturally relevant perspective. The conference provides a supportive environment with professionals and peers and an enhanced cutting-edge educational experience via motivational speakers, presentations, demonstrations, posters, developmental workshops and panel discussions. The 2019 conference was organized by 5 Steering Committee (SC) members (including the conference coordinator, and assistant coordinator). The conference was attended 
by staff and 235 attendees: 150 students from the Minnesota Area (including Wisconsin, Iowa, South Dakota, and North Dakota), 50 students from other states, and 35 presenters.

\section{Theoretical Framing}

The [YU?] program can be examined using the theoretical framing of the Social Community Model to better understand participants' community experiences. A social community is "an environment where like-minded individuals engage in dynamic, multi-directional interactions that facilitate social support" which is significant in improving long-term student outcomes [27]. Social community is thus composed of two different major components. The first is program elements, which includes program values, faculty and peer access, demonstrated in things such as tutoring, informal study groups, and small group TA sessions, and formal and informal group activities. The second component is social support. Social support is defined as the connectedness that participants feel to a community, and is manifested through things such as supportive actions and behaviors, the availability of actual support, global evaluations of quality and availability, and social roles and relationships [28]. This concept of connectedness is defined as how linked the participant feels to their program community, and will be the primary concept discussed in the paper. Overall, all of the elements of social community work to produce participant outcomes, (e.g., resiliency, communities of practice, and social capital) which help increase the retention of African Americans in STEM fields.

\section{Methods}

In this study, we used a phenomenological, mixed methods approach [29] that included a survey with both multiple choice and short answer portions. The primary aim was to look at the topic of connectedness of STEM students who participated in the [YU?] conference, a professional development and mentoring conference for minoritized populations, primarily attended by African Americans.

\section{Sample}

The sample size is comprised of participants of the [YU?] organization who attended the conference on March 29-30, 2019. Before the conference, a Google form was sent out requesting volunteers to take the pre-survey. An hour after the conference began, the initial respondents were sent the pre-survey via email. On the last day of the conference, the postsurvey was sent to the same set of participants. Students who completed both surveys were given a $\$ 10$ gift card as financial compensation for their participation.

Originally, the pre-survey was completed by 24 students, and the post-survey by 15 . Seven of the pre-survey responses were incomplete, leaving 17 full responses. Regarding the post-survey, two of the responses were from a participant who did not complete the pre-survey-instead, they completed the post-survey once within a day of the end of the conference and then again four days later, with wildly different responses. Additionally, another participant noted in the long 
response section of the post-survey that they were not a member of the [YU?] organization.

Finally, the participant with the greatest total change in average answers was entirely negative in the multiple choice section of the survey, but entirely positive in their written response, so due to the inconsistent nature of their recorded response, their response, as well as the other 3, were all discounted. The remaining 11 post-survey responses were then all matched with pre-surveys via the emails provided, and assigned participant numbers to maintain anonymity in analysis. The paired data was what was primarily used in analysis.

Respondents primarily identified as Black or African American, were nearly all undergraduates, and slightly majority female, see Table 1 . The youngest participant was 18 , and the oldest was 29.

Table 1 Descriptive Statistics for the Sample

\begin{tabular}{ll}
\hline Gender & \\
Female & $6(54.5 \%)$ \\
Male & $5(45.5 \%)$ \\
& \\
Race & $1(9.1 \%)$ \\
Asian & $8(72.7 \%)$ \\
Black or African American & $1(9.1 \%)$ \\
Hispanic or Latino & $1(9.1 \%)$ \\
White/Non-Hispanic & \\
Academic Standing & $2(18.2 \%)$ \\
Graduate & $9(81.8 \%)$ \\
Undergraduate & \\
Age & 22.4 \\
Mean & $18-29$ \\
Range & \\
Citizenship Status & $10(90.9 \%)$ \\
United States Citizen & $1(9.1 \%)$ \\
Other & \\
GPA & 3.28 \\
Mean & $2.9-3.75$ \\
Range & \\
\hline
\end{tabular}

\section{Data Collection}

On the pre-survey, students answered a total of 15 multiple choice questions using a Likert scale of 1 to 5 with response options of Strongly Agree to Strongly Disagree. The first four questions were asked to measure STEM interest. The following 11 questions were asked on both the preand post-surveys and focused on their feelings of connectedness towards the other participants of 
the [YU?] program. In addition, the post-survey asked 6 open-ended qualitative questions about the students' program experiences, also focusing on connectedness.

\section{Data Analysis \\ Quantitative Analysis}

The 11 questions that overlapped between the two surveys were the focus of the analysis. Although the questions were asked on a Likert scale from "Strongly Disagree" to "Strongly Agree," for the purpose of statistical analysis the ordinal data was then converted to a 1-5 scale, with "Strongly Disagree" corresponding to 1 and "Strongly Agree" corresponding to 5, assuming the responses were equal distances apart.

All but three of the questions were worded positively, i.e. an answer of 5 indicated a positive experience in the program. Thus, for the purpose of consistency in analysis, the scales of the reverse-coded questions were flipped, making 1 correspond to "Strongly Agree."

First, basic statistics were calculated to see major trends in the data: mean and standard deviation of each question over all the participants, as well as the mean and standard deviation for each respondent for the 11 repeated questions. Then, the change in mean and standard deviation for each question and each respondent was calculated.

Additionally, a one-sided, paired, two-sample t-test for means was performed in Microsoft Excel to see if any changes were significant. This test was chosen because the one-to-one correspondence between the samples meant that it was paired, and because the changes in mean were positive for all 11 questions, only significance in the positive direction was analyzed, allowing the use of a one-sided test [31, 32].

After that analysis was finished, the data was re-analyzed with the excluded results. This data set utilized a one-sided, two-sample, t-test assuming unequal variances in Excel, because the inclusion of the excluded data meant that it was no longer a before-and-after of the same data set, and calculations showed that the variances of the two new sets for each question were not equal. Similar to the cleaned data set, all but two changes in mean were still positive. While 9 of the 11 mean changes were deemed significant in the cleaned set, none of the changes in the non-cleaned set were. However, in the full set of results there were 17 pre-survey responses but only 15 for the post-survey, which could have made the change less drastic. Overall, because the full set exhibited the same general trends as the cleaned set, the cleaned set was used for the rest of the analysis, and will be discussed in the results.

Additionally, the data was separated by sex and re-analyzed to see if that showed any significant difference. There were minor differences between the men and women in both directions in both the pre-survey and post-survey questions, so a two-tailed t-test assuming unequal variances was 
performed comparing the men's pre-survey question answers with the women's, and the same with the post-survey.

Finally, the data was also analyzed by race. There were eight students in the sample who identified as Black and three as Non-Black. Another two-tailed t-test assuming unequal variances was performed comparing the Black students' pre-survey question answers with the Non-Black students', and the same with the post-survey.

\section{Qualitative Analysis}

An iterative and grounded theory coding process was used, in which the 6 qualitative survey questions, see Table 2, were sorted into groups based on the information they elicited: Motivation/Expected Outcomes, Takeaway(s)/Experience(s), and Program Review. Quotes relating to the primary theme of connectedness were extracted and interpreted. In addition, the word "network" was a common theme in the responses, and relates to connectedness in a business sense, so the quotes were re-read to point out any mention of networking in the Motivation category, where it primarily appeared.

Table 2 Qualitative Questions

1. What is your academic status?

2. What was your primary goal in attending this conference?

3. What have you learned during your time in the program?

4. What has been the most memorable part of your program experience?

5. What do you like about the [YU?] Program?

6. What do you dislike about the [YU?] Program?

\section{Quantitative Results}

\section{Results}

In regards to the first four questions regarding STEM interest, students responded with an overall mean of 3.23, with the highest mean in science interest, of 3.91, and the lowest in math interest, of 2.64. In the primary 11 questions, which were asked on both surveys, the mean of all the presurvey responses was 2.98, and the post-survey mean was 3.85. All 11 questions increased in their individual mean responses as well, with the largest increase in question 1 of 1.27 , and the smallest increase in question 8 of 0.18 . While in the pre-survey questions, the most common response was neutral, in the post survey, this shifted to agree, as seen in Figure 1. 

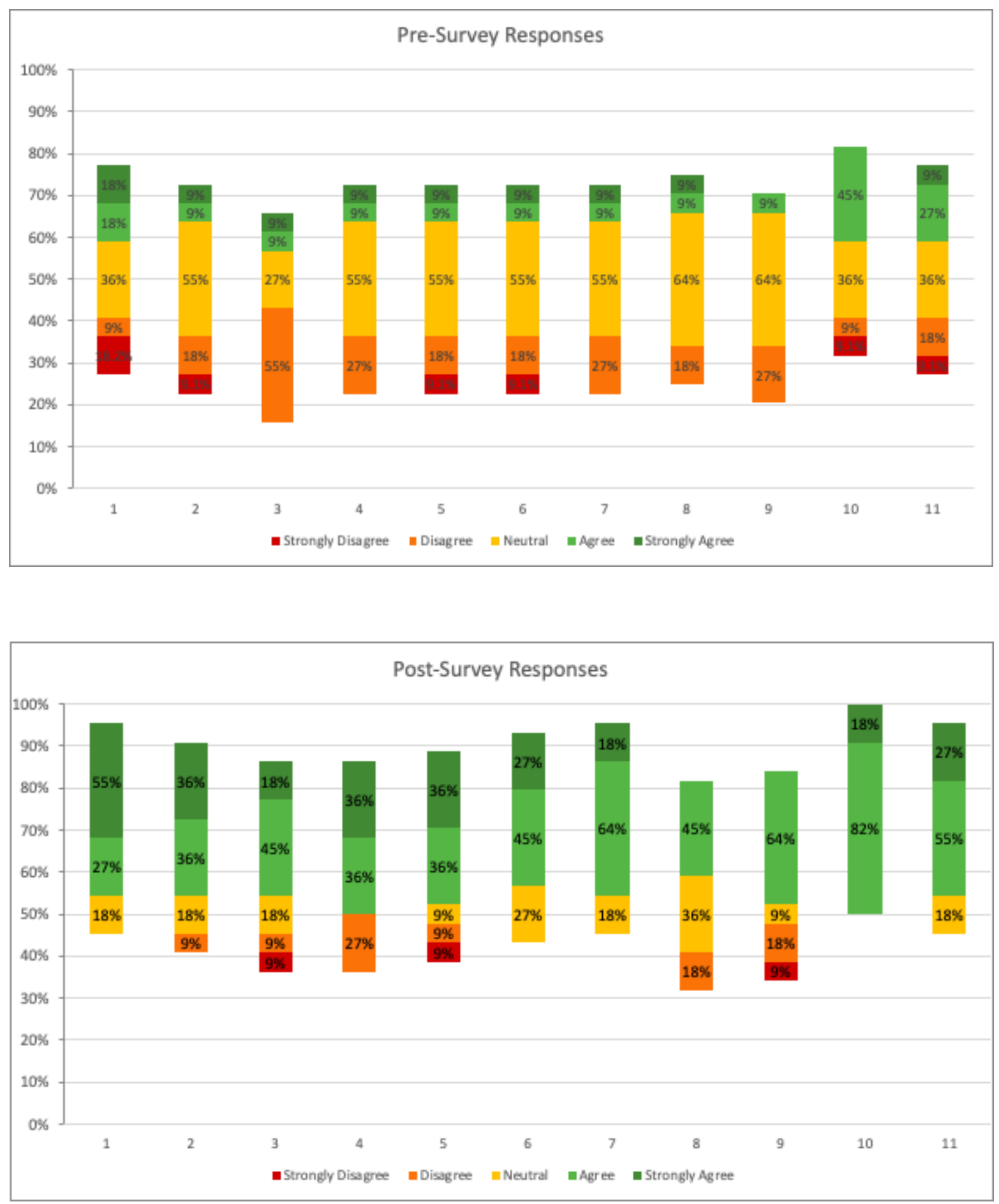

Figure 1 Percentages of Each Response on the Pre- and Post-Surveys

As per the t-test, four of the changes in the questions were deemed significant at the 0.01 level, another three at the 0.05 level, and another two at the 0.1 level, meaning nine of the 11 questions were deemed significant, all but questions 8 and 9, see Table 3 . 
Table 3 Paired Quantitative Questions with Significance

\begin{tabular}{|c|c|c|c|}
\hline $\begin{array}{l}\text { Question } \\
\text { Number }\end{array}$ & $\begin{array}{l}\text { Question } \\
\text { Text }\end{array}$ & $\begin{array}{l}\text { Mean } \\
\text { Change }\end{array}$ & $\begin{array}{l}\text { T-Test } \\
\text { Significance }\end{array}$ \\
\hline 1 & $\begin{array}{l}\text { I feel that students in the [YU?] Program care about each } \\
\text { other. }\end{array}$ & 1.273 & $0.007 * * *$ \\
\hline 2 & I feel connected to others in the [YU?] Program. & 1.091 & $0.007 * * *$ \\
\hline $3^{*}$ & I do not feel a spirit of community in the [YU?] Program. & 0.818 & $0.054 *$ \\
\hline 4 & $\begin{array}{l}\text { I have found a sense of family as a student in the [YU?] } \\
\text { Program. }\end{array}$ & 0.818 & $0.028 * *$ \\
\hline $5^{*}$ & I feel isolated in the [YU?] Program. & 0.909 & $0.053 *$ \\
\hline 6 & I trust friends that I have in the [YU?]Program. & 1.091 & $0.005 * * *$ \\
\hline 7 & I feel that I can rely on others in the [YU?] Program. & 1.000 & $0.002 * * *$ \\
\hline 8 & I feel that students in the [YU?] Program depend on me. & 0.182 & 0.320 \\
\hline 9 米 & I feel uncertain about others in the [YU?] Program. & 0.455 & 0.121 \\
\hline 10 & $\begin{array}{l}\text { I feel confident that others in the [YU?] Program will } \\
\text { support me. }\end{array}$ & 1.000 & $0.013 * *$ \\
\hline 11 & $\begin{array}{l}\text { When I feel like I'm having academic difficulties, there } \\
\text { are people I can seek support from. }\end{array}$ & 1.000 & $0.013 * *$ \\
\hline
\end{tabular}

Note: * signifies a reverse-coded question. ${ }^{*} \mathrm{p}<0.1,{ }^{*} \mathrm{p}<0.05, * * * \mathrm{p}<0.01$.

For the two-tailed t-tests assuming unequal variances performed on both the data when it was split by sex and when it was split by race, none of the questions were significant at the $0.1,0.05$, or 0.01 levels.

\section{Qualitative Results}

Looking at the primary construct of connectedness, there were two themes that emerged in analysis: students felt that other students in the program were kind, but they also felt that networking was not adequately facilitated. Overall, this demonstrated that students considered the [YU?] conference as a good place to connect with others, although acknowledging that more program support was needed. 


\section{Qualitative Theme \#1: Peer Interaction}

Students were highly positive when speaking about the other members of the program with 6 out of the $11(55 \%)$ specifically noting how their interactions with the other participants were a positive part of the conference. One student said that:

I love the sense of community you get while being in this program. Everybody is so respectful to one another and help each other in tremendous ways.

Another student also indicated that being with others who were facing the same challenges made them feel empowered. He said:

My goals are achievable because there are others out there like me who faced the same struggles and hurdles but overcame and are successful.

Likewise, students seem to appreciate the interactions with others. A third student indicated that "the feeling of family and how open everyone is" was one of his favorite parts of the conference.

Clearly, not only do students make friends in the program, but the connections they make help them become more capable professionals. Additionally, the only remotely negative feedback about the willingness of other participants to connect was from two students who noted that it was not clear if the event was meant for non-Black people of color (POC). One participant, who identified as Black, stated:

Some of the other students weren't welcoming to the non-Black people of color.

And another, who identified as Asian, lamented and said:

[There was a] lack of representation for other students of color who did not identify as being Black, African, or African American.

However, this was a small portion of the response group, and only one of the three non-Black people of color expressed feeling out of place. In addition, a White student mentioned appreciating a presentation that provided him with a different cultural perspective. He said:

[I liked the] presentation [Cultural Enlightenment: Examining the Pejorative "N-Word"]. It was very eye opening for me to see the perspective of other cultures and what issues they face.

In sum, participants' experiences varied between students. 


\section{Qualitative Theme \#2: Networking}

Although the responses were strongly positive about the friendliness of students, several responses noted that the logistics of the conference were an impediment to building connections. Networking was clearly a priority, as eight out of the $11(73 \%)$ students mentioned it as a goal for the conference, and four (36\%) also noted that there was not adequate time to mix with the other participants. One student, wrote that the most memorable part of the program was the networking. He recounted:

Being able to network and share our experiences teaches each person a new thing.

However, another respondent said:

We could not network at the end because everyone was busy and leaving.

And another also mentioned:

I wish there was more... networking happening, whereas having to constantly go to one presentation after another.

This indicates that there was a clear desire to connect with other students, but more time was needed to allow students to connect as they had hoped.

\section{Discussion}

From the data, the primary theme was the students' experienced increased connectedness attending the conference, particularly through networking, despite a few students' dissatisfaction with the diversity of the audiences. The theme of increased connectedness was supported by both the quantitative data, which had several questions that had significant mean changes indicating increased connectedness, and the qualitative data, in which several students noted that the other program participants were a primary factor in their growth at the conference. However, four students did note that they wished they had had more time to network, which is significant given that eight out of 11 , or $72.7 \%$, listed networking as one of their main goals for the conference. In addition, two students felt the conference should include and recruit more people of color. Although it did not keep the overall conference experience from being positive for most students, this dissension could be a barrier to building community.

\section{Overall Increase in Connectedness}

The initial expectation for the conference was that connectedness would increase for students. This did prove to be true, with a pre-survey mean on the 11 connectedness questions of 2.98 , and a post-survey mean of 3.85 , with each individual question's mean increasing as well. A onesided paired t-test showed that nine of the 11 increases in mean were significant at a level of at 
least 0.1 . The qualitative portion in the post-survey also supported these results - overall, students were incredibly positive about their time at the conference, as well as about the other participants.

The overall increase is possibly due to the students being able to spend time with other participants in person and seeing members outside of their specific conference area. In particular, outside of the conference, students are primarily involved with the [YU?] mentoring program virtually, aside from another small conference. This may make it more difficult to bond with other students, especially because outside of the conference students mostly communicate with their mentor. Of the two increases that were deemed insignificant, one of the questions asked about feeling uncertain about others, which might have been confusing to the students, and therefore would not have shown the same level of increase as the other question responses.

More notably, the other question that was deemed insignificant asked about feeling that "students in the [YU?] Program depend on me." The conference was primarily structured around presentations to help the students learn from more established professionals, in contrast to a formal peer mentoring structure. Therefore, students might see their [YU?] peer relationships solely as friends and peers, and would depend more on their assigned mentors. The desire for more networking time could also explain why students did not feel strongly about others relying on them-if there was minimal time to network, they might not have felt like they contributed much to their peers, simply due to time constraints. In addition, the increase in connectedness also held true when the data was analyzed by gender, indicating that gender was not a major factor in the growth of connectedness during the conference.

As stated earlier, the main program elements of mentoring programs are (a) program values, (b) access to faculty and peers, and (c) formal and informal group activities [21, 22, 23, 24, 25]. The [YU?] conference, a part of the larger [YU?] organization, has all three: supporting minoritized students, providing access to peer conference attendees and professional speakers, and gathering together [YU?] members. Likewise, increased community due to participation in a mentorship program that provides social support and access to faculty, peers, and resources may have beneficial long-term outcomes $[15,16]$.

Overall, the primary takeaway from the data was that the conference served its purpose of giving minoritized students a place to spend time together and connect, which is important because all students need community to succeed. Although some students did offer critiques in their comments, there was a clear overall trend of students becoming more connected after the conference, and these critiques could all be easily addressed.

\section{A Need for More Networking}

Within the theme of increased connectedness, networking also emerged as a key sub-theme. Eight out of 11 students $(72.7 \%)$ indicated that networking was one of their main goals for the 
conference, but four of the students noted not having enough time or wanting more time to network. This could be because much of the program was highly structured, composed primarily of talks, leaving little time designated for students to interact aside from two shorter networking "breaks" which were combined with a poster session and photographs. This could be easily changed for next year's conference by adding full sessions that are more interactive and focused on connecting students in a professional conference, thus allowing students who wanted more time to add that to their schedules. Students clearly highly value and want to engage with the community. This indicated that students might want more networking not only out of a desire to advance their own careers, but also to help each other. By adding more time for it, it would also hopefully help students feel like others rely on them, which on a higher level ties them more strongly to community. Also, we note that although the main portion of the conference was highly structured and there were several evening activities for students to attend for networking and bonding purposes. Those activities included a conference mixer/reception, etiquette dinner, energy-busting indoor games and a vision board development activity.

\section{Clarification about the Intended Audience}

Also within the theme of increased connectedness, a second sub-theme emerged: the intended audience of the conference. The [YU?] website states that it exists to serve minority students [30]. Due to the website's stated purpose, Non-Black students, especially those unaffiliated with the [YU?] organization, may have anticipated a more diverse group of attendees and speakers. In contrast, Black students might have not expected students of other races to attend a conference that primarily focused on Black issues. The conference featured presentations on the n-word and on diversity, and the majority of the presentations except one were given by Black people, so non-Black students may not have felt the conference was relevant to them. Even so, this was only brought up by one of the three non-Black students. One of the other two non-Black students listed discussions about social justice issues as one of his favorite parts of the conference, and the other said that making new friends was a positive, so experiences were quite varied. This makes sense especially due to the extremely small sample size of only three nonBlack students. In the future, the conference committee should maybe strategically target students from other minoritized groups to help increase the diversity of the attendees.

\section{Limitations}

Overall, this study had a few key limiting factors. First, a sample size of only 11 students, the majority of whom were Black, allowed for little depth in statistical analysis. Second, the reverse coded questions may have confused some students on the meaning of their responses, which could have negatively impacted the averages, as a number of students were overall positive, but answered negatively on the reverse coded questions. Future research should allow for a more comprehensive review of the conference participants' experiences. 


\section{Conclusions}

In this paper, we analyzed the experiences of minoritized students, primarily African Americans, before and after attending the [YU?] organization's annual conference. This was accomplished by analyzing how conference attendance affected the experience of connectedness for students. Overall, the conference itself was successful in accomplishing its goals of eradicating barriers to students' and young professionals' success by effectively delivering longitudinal support, here via the form of peer relationships. Continuing the conference helps even more minoritized students to develop a sense of community to help offset the unique struggles they face. The primary insight gleaned from the study was that overall, the conference increased a sense of connectedness, even when disaggregated by gender and race. Students had a clear desire to support one another, and the only critical theme was a desire to have more structured networking time, which could also further facilitate connectedness. Generally, other studies have found that conferences and programs tend to have positive benefits for minoritized students. However, connectedness has not been heavily researched, so more research in this area can build upon this exploratory study's findings.

\section{Acknowledgements}

The authors would like to thank Anu Tuladhar and Sarah Jane Bork for their contribution to this work. 


\section{References}

[1] Hossain, M., \& Robinson, M. G. (2012). How to Motivate US Students to Pursue STEM (Science, Technology, Engineering and Mathematics) Careers. US-China Education Review. Retrieved from https://files.eric.ed.gov/fulltext/ED533548.pdf

[2] U.S. Census Bureau (2011). 2010 Census Shows Black Population has Highest Concentration in the South. Retrieved from https://www.census.gov/newsroom/releases/archives/2010_census/cb11-cn185.html

[3] U.S. Census Bureau (2013). Disparities in STEM Employment by Sex, Race, and Hispanic Origin. Retrieved from https://www.census.gov/library/publications/2013/acs/acs-24.html

[4] Yoder, B. L. (2017). Engineering by the Numbers. ASEE. Retrieved from https://www.asee.org/documents/papers-and-publications/publications/collegeprofiles/2017-Engineering-by-Numbers-Engineering-Statistics.pdf

[5] Harris, A. (2019, April 19). The Disciplines Where No Black People Earn Ph.D.s. The Atlantic. Retrieved from https://www.theatlantic.com/education/archive/2019/04/lack-ofblack-doctoral-students/587413/

[6] Harper, C. (2018, May 14). Retrieved from https://www.higheredtoday.org/2018/05/14/hbcus-black-women-stem-success/

[7] Burt, B. A., Williams, K. L., \& Smith, W. A. (2018). Into the Storm: Ecological and Sociological Impediments to Black Males' Persistence in Engineering Graduate Programs. American Educational Research Journal, 55(5), 965-1006. doi: $10.3102 / 0002831218763587$

[8] Nelson, D. J., \& Brammer, C. N. (2010). A National Analysis of Minorities in Science and Engineering Faculties at Research Universities (2nd ed.).

[9] Alvarez, A. N., Blume, A. W., Cervantes, J. M., \& Thomas, L. R. (2009). Tapping the wisdom tradition: Essential elements to mentoring students of color. Professional Psychology: Research and Practice, 40(2), 181-188. https://doi.org/10.1037/a0012256

[10] Adams, H. G. (1994). Creating a Campus Climate That Supports Academic Excellence. National Consortium for Graduate Degrees for Minorities in Engineering and Mathematics, Inc. Retrieved from https:/files.eric.ed.gov/fulltext/ED381066.pdf

[11] Cabrera, A. F., Nora, A., Terenzini, P. T., Pascarella, E., \& Hagedorn, L. S. (1999). Campus Racial Climate and the Adjustment of Students to College. The Journal of Higher Education, 70(2), 134-160. doi: 10.1080/00221546.1999.11780759

[12] McClain, O.L., Negotiating Identity: A Look at the Educational Experiences of Black Undergraduates in STEM Disciplines. Peabody Journal of Education, 2014. 89(3): p. 380-392.

[13] Strayhorn, T. L. (2010). Buoyant believers. In M. C. Terrell \& T. L. Strayhorn (Eds.), The evolving challenges of black college students: New insights for policy, practice, and research (pp. 49-65). Sterling, VA: Stylus Publishing, LLC. 
[14] Zalaquett, C. P., \& Lopez, A. D. (2006). Learning from the stories of successful undergraduate Latina/Latino students: the importance of mentoring. Mentoring \& Tutoring: Partnership in Learning, 14(3), 337-353. doi: 10.1080/13611260600635563

[15] Mondisa, J. L., \& McComb, S. A. (2015). Social Community: A Mechanism to Explain the Success of STEM Minority Mentoring Programs. Mentoring \& Tutoring: Partnership in Learning, 23(2), 149-163. doi:10.1080/13611267.2015.1049018

[16] Ortiz-Walters, R., \& Gilson, L. L. (2005). Mentoring in academia: An examination of the experiences of protégés of color. Journal of Vocational Behavior, 67(3), 459-475. doi: 10.1016/j.jvb.2004.09.004

[17] Stolle-McAllister, K. (2011). The Case for Summer Bridge: Building Social and Cultural Capital for Talented Black STEM Students. Science Educator, 20(2). Retrieved from https://files.eric.ed.gov/fulltext/EJ960632.pdf

[18] Maton, K.I., et al., Outcomes and processes in the Meyerhoff scholars program: STEM PhD completion, sense of community, perceived program benefit, science identity, and research self-efficacy. CBE—Life Sciences Education, 2016. 15(3): p. Ar48.

[19] Murphy, T. J., Stafford, K. L., \& McCreary, P. (1998). Subsequent course and degree paths of students in a Treisman-style workshop calculus program. Journal of Women and Minorities in Science and Engineering, 4, 381-396.

[20] Shultz, E. L., Colton, G. M., \& Colton, C. (2001). The Adventor Program: Advisement and Mentoring for Students of Color in Higher Education. The Journal of Humanistic Counseling, Education and Development, 40(2), 208-218. doi: 10.1002/j.2164490x.2001.tb00118.x

[21] Ehrich, L. C., Hansford, B., \& Tennent, L. (2004). Formal mentoring programs in education and other professions: A review of the literature. Educational Administration Quarterly, $40,518-540$.

[22] Gershenfeld, S. (2014). A review of undergraduate mentoring programs. Review of Educational Research, 84, 365-391.

[23] Hrabowski, F. A., \& Pearson, W., Jr. (1993). Recruiting and retaining talented AfricanAmerican males in college science and engineering. Journal of College Science Teaching,

[24] Maton, K. I., Hrabowski, F. A., \& Schmitt, C. L. (2000). African American college students excel- ling in the sciences: College and postcollege outcomes in the Meyerhoff Scholars Program. Journal of Research in Science Teaching, 37, 629-654.

[25] Treisman, P. M. (1992). Studying students studying calculus: A look at the lives of minority mathematics students in college. The College Mathematics Journal, 23, 362-372.

[26] Mondisa, J. L., \& McComb, S. A. (2018). The role of social community and individual differences in minority mentoring programs. Mentoring \& Tutoring: Partnership in Learning, 26(1), 91-113. doi: 10.1080/13611267.2018.1445432 
[27] Mondisa, J. L., \& McComb, S. A. (2014). Social community: Understanding students' connectedness to promote student success. Paper presented at the 2014 Industrial and Systems Engineering Research Conference, Montreal, Canada.

[28] Lakey, B., \& Cohen, S. (2000). Social support theory and measurement. In S. Cohen, L. Underwood, \& B. Gottlieb (Eds.), Social Support Measurement and Intervention: A Guide for Health and Social Scientists (pp. 29-52). New York, NY: Oxford University Press.

[29] Creswell, J. W., \& Creswell, J. D. (2017). Research design: Qualitative, quantitative, and mixed methods approaches: Sage publications.

[30] The "Why You?" Initiative [YU?]. (n.d.). About Us. Retrieved July 17, 2019, from https://www.whyyou.org/?page_id=87

[31] Pillemer, D. B. (1991). One- Versus Two-Tailed Hypothesis Tests in Contemporary Educational Research. Educational Researcher, 20(9), 13-17. doi:

10.3102/0013189x020009013

[32] McCrum-Gardner, E. (2008). Which is the correct statistical test to use? British Journal of Oral and Maxillofacial Surgery, 46(1), 38-41. doi: 10.1016/j.bjoms.2007.09.002 